\title{
The Method to Solve Problems About Fraction by Using the Manipulative Media
}

\author{
Nurul Astuty Yensy*
}

\author{
Mathematics Education Study Program, University of Bengkulu \\ *Corresponding author. Email: nurulastutyyensy@unib.ac.id
}

\begin{abstract}
Mathematics has an important role in the world of education because it supports science in other fields, such as physics, chemistry, biology and science. Mathematics learning is abstract, so mathematics learning should be carried out in a fun, interesting manner and easily understood by students. One of them was the material on the concept of fractions and their operations that have been studied at the elementary school level. Based on the previous research, this material was still found difficult to understand by students, especially if the denominators were different. Usually, the teacher uses the conventional method, namely equating the denominator of the fraction by determining the Biggest Guild Multiples. It is very rare for teachers to use assistive media in learning these fractions. Therefore, this article discusses the alternative method to solve problems about fractions by using manipulative media, namely media in the form of paper that can be turned, cut, shifted, moved, drawn, sorted, grouped and classified. This type of research was a literature study, using secondary data in the form of journals and relevant books. Furthermore, the data were analyzed by conducting studies on examples of solving fraction problems by using manipulative media, assessing their advantages and also disadvantages and comparing them with the conventional methods. The results showed that solving fraction problems by using the manipulative media was more fun, more attractive in terms of appearance and easier to understand because of direct practice using the media. It is suggested that teachers can apply this alternative method in the class, especially for students who do not understand the conventional methods in solving the fraction problems.
\end{abstract}

Keywords: Fraction Concept, Alternative Method, Manipulative Media.

\section{INTRODUCTION}

Mathematics is a field of study that exists at all levels of education, from elementary school until college. However, mathematics is a subject that is considered difficult and confusing for most students, especially students in elementary school. Thus, the teaching of mathematics at the elementary school level should receive more serious attention because it is the basis of learning mathematics and occurs during elementary school [1].

Basic mathematics is given at the basic education level because this level is a very decisive foundation in shaping children's attitudes and skills that are useful for the next life [2]. The learning process activity expects every student to learn to be beneficial and their learning is meaningful, but the reality shows that mathematics is difficult for students. Many students are constrained in learning mathematics, this is a result of the learning process is not interesting, and boring. This directly affects mathematics learning achievement at every level of education.

Teachers in planning a learning process, at least the factors that generally have to be considered simultaneously by the teacher include: the objectives to be achieved, the learning materials, students, the teaching media, the learning methods and the study time [3] Without ignoring the other factors, these factors together determine the results of the learning process that occurs. The quality and productivity of this learning will be seen in how far students achieve the learning objectives that have been set. Meanwhile, to make students achieve predetermined learning goals is closely related to the effectiveness of the learning strategies prepared by the teacher. For this reason, one of the teacher's duties is how to organize an effective learning so that it is more varied, interesting and fun [4].

However, reality [5] showed that most teachers still have difficulty how to organize effective learning, especially mathematics learning in elementary schools. 
Learning that is carried out is still teacher-centered, and an abstract approach with lecture and assignment methods is very dominant in every learning activity. It is very rare to find teachers who plan mathematics learning with a real approach that activates students, because they consider such learning to be useless, confusing and time-consuming. In addition, the facts show that elementary school teachers are still inadequately equipped with mathematics material.

Furthermore, a teacher should teach mathematical concepts using varied methods and techniques so that they are not monotonous and boring for students such as the "fun learning" method [6]. One method of "fun learning" is to use the aid of teaching aids or media to instill the concept of understanding the material into students. The actual props should be made available in schools so that the understanding given to students can be more easily captured [7]. Props can present abstract things in the form of concrete objects or phenomena that can be seen, held, changed so that abstract things are easier to understand. Also, with teaching aids, learning becomes more fun because students can learn while [8].

One type of props is manipulative objects. The manipulative objects are tools to explain the mathematical concepts by using certain concrete objects that will assist students in representing a concept correctly. Mathematical manipulation and models are very important tools for making the students communicate mathematical ideas and concepts [9]. Using manipulative objects (teaching aids) can facilitate students in learning mathematics, in addition to the ability to recognize, understand, apply mathematical concepts, procedures, principles and ideas, the ability to solve mathematical problems, the ability to reason mathematics, and the ability to make mathematical connections. "Students can use the visual models to develop computation skills or solve contextual problems" [10].

In order for the mathematics learning process to attract the attention of students, the learning must involve the student. So that students get direct experience from the learning process and the learning becomes fun. The manipulative objects are one of the media that can attract students' interest to be actively involved in learning. The importance of using teaching aids in mathematics learning is to assist students in grasping the understanding given by the teacher and reducing the occurrence of verbalism [11]. Furthermore [12] said that one of the mathematical concepts that is difficult to understand concretely and allows misconceptions and verbalism to occur is the concept of fractions. Theoretically, the concept of fractions is a more difficult topic than integers [13]. Moreover, [14] stated that in learning the concept of fractions it is very possible for students to misconceptions. The difficulty of students understanding the concept of fractions is suspected because they have difficulty digesting it in real terms. In fact, conveying abstract mathematical concepts requires a model as an illustration. In conveying the concept of fractions, a learning process is needed that facilitates students to master and develop these concepts in everyday life, so it requires the use of appropriate teaching aids, one of which is manipulative objects. Usually, the teacher uses the conventional method, which is to equalize the denominator of the fraction by determining the Multiples of the Largest Guild, but this method often causes misconceptions by students.

Based on this, this article discusses the alternative methods of solving fraction problems by using the manipulative media, namely media in the form of paper that can be turned, cut, shifted, moved, drawn, sorted, grouped or classified so that it can be studied and analyzed how the comparison is when using the. conventional method.

\section{RESEARCH METHODS}

The type of research was a literature study, by using secondary data, namely journals and relevant reference books. Furthermore, the data were analyzed, namely by conducting an assessment on the example of solving problems about the addition of fractions by using the manipulative media, examining the advantages and disadvantages and comparing them with conventional methods.

How to create manipulative media like the following [15]:

1. Make a circle or square shape from manila paper

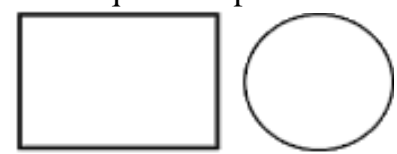

2. Shade in half from one side to show the fraction one by two

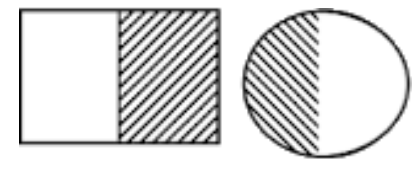

3. The unshaded circle or square (the face) represents the number 1

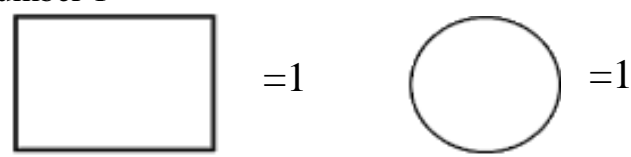

4. Fold the face so that it becomes two equal parts

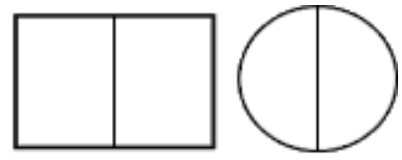

5. The part shaded in step $2=$ half of the face

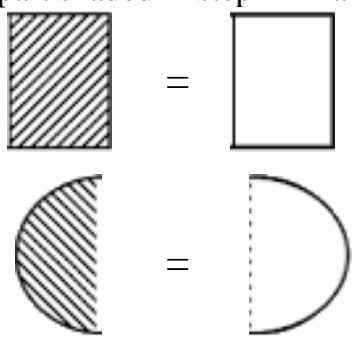


The steps for creating the manipulative media for fraction operations are as follows:

1.1. Prepare white plywood, and then cut it into sizes 50 $\mathrm{cm} \times 50 \mathrm{~cm}$.

1.2. Cut the red and yellow mangosteen paper into several pieces, each piece $5 \mathrm{~cm} \times 10 \mathrm{~cm}$.

1.3. Give the foam adhesive tape to each piece of mangosteen paper so that it can be attached to the plywood.

\section{RESULTS AND DISCUSSION}

\subsection{Explaining the Concept of Fractions by Using Conventional Methods}

The fraction numbers are numbering whose symbols can be written with the form $a / b, a, b$ are integers; $b \neq 0$ and $b$ is not a factor of $a[16]$, on fraction $a / b$, $a$ is called the numerator and $\mathrm{b}$ is called the denominator of the fraction. The equal fraction is the fraction with the same value, by multiplying or dividing the numerator and denominator by the same number [17].

\section{Example 1:}

Find two fractions that are equal to the fraction $1 / 2$

The Answer:

Fraction $1 / 2$ can be searched the fraction that is equal by multiplying the numerator (1) and denominator (2) by the same number, for example multiplying by the numbers 2 and 4 . Then the result is:

$\frac{1}{2}=\frac{1 \times 2}{2 \times 2}=\frac{2}{4}$

$\frac{1}{2}=\frac{1 \times 4}{2 \times 4}=\frac{4}{8}$

Thus, two fractions that equal to $1 / 2$ are $2 / 4$ and $4 / 8$.

\section{Example 2:}

Find three fractions that equal to the fraction $1 / 4$

The Answer:

Fraction $1 / 4$ can be found for equal fractions by multiplying the numerator (1) and denominator (4) by the same number, for example multiplying by the numbers 2, 3 and 4 . Then the result is:

$\frac{1}{4}=\frac{1 \times 2}{4 \times 2}=\frac{2}{8}$

$\frac{1}{4}=\frac{1 \times 3}{4 \times 3}=\frac{3}{12}$

$\frac{1}{4}=\frac{1 \times 4}{4 \times 4}=\frac{4}{16}$

Thus, three fractions that equal $1 / 4$ are $2 / 8 ; 3 / 12$, and 4/16.

Example 3:

Find the sum of the following fractions: $\frac{1}{2}+\frac{1}{3}$

The answer:

If the fraction is solved in a conventional way, by equalizing the denominator, that is, looking for the multiplication of the largest common denominator, then we get $=6$

So, $\frac{1}{2}+\frac{1}{3}=\frac{1 \times 3}{2 \times 3}+\frac{1 \times 2}{3 \times 2}=\frac{3}{6}+\frac{2}{6}=\frac{5}{6}$

Based on the example of the solution above, it can be seen that by using conventional methods, the student must first understand the concept of multiplication of integers and must also be skilled at determining the greatest common multiple of the denominator of fraction. This method also does not make the student understand the basic concept of fraction, because they are still abstract. The student actually also do not understand the real meaning of the equal fraction, resulting in misconceptions among the student. This is in accordance with what was stated by [18]: "Errors are the symptoms of the underlying conceptual structures that are the cause of errors. It is these underlying beliefs and principles in the cognitive structure that are the cause of systematic conceptual errors that I shall call misconceptions".

\subsection{Explain the Concept of Fraction by Using Manipulative Media}

The manipulative media are the assistive media to explain the concept of fraction by using concrete objects such as Manila paper that can be folded, shifted, and so on. So that the fraction material is more real and students can easily imagine the material being studied. The use of manipulative media is intended to make it easier for students to understand mathematical concepts and procedures. This manipulative media serves to simplify difficult concepts, present relatively abstract materials to be more real, explain definitions or concepts more concretely, explain certain properties related to calculating (operations), the properties of geometric shapes and show the facts.

In learning mathematics, it is better if the learning materials provided are easier for student to understand, the material that need to be prepared by the teacher, from items that are relatively cheap and easy to obtain, for example Manila paper, cardboard, wood, wire, cloth to embed. specific mathematical concepts according to necessity.

For example, explain the concept of the equal fraction as follows:

1. Explain that $2 / 3$ is equal to $4 / 6$ by using the manipulative media: 

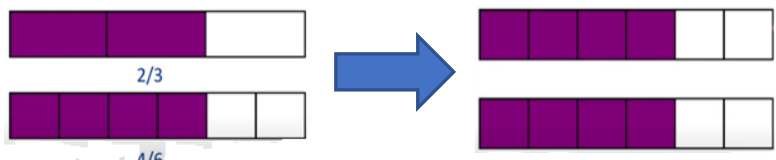

$4 / 6$

In the picture above, it can be explained as follows: the fractional image $2 / 3$ if put together with a fraction image $4 / 6$ then the shaded area will coincide, meaning that the shaded area for the fraction $2 / 3$ will be the same as the shaded area for the fraction $4 / 6$, so $2 / 3$ can be said to be equal to $4 / 6$.

2. Explain that the fraction $1 / 2$ is equal to $2 / 4$ and also equal to $4 / 8$

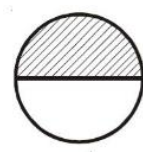

(i) $=\frac{1}{2}$

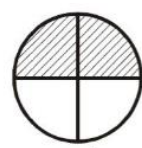

(ii) $=\frac{2}{4}$

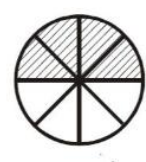

(iii) $=\frac{4}{8}$
In the picture above, it can be seen that the shaded area for the fraction $1 / 2$ is the same as the shaded area for the fraction $2 / 4$ and also the shaded area for the fraction 4/8. Thus students immediately understand the concept of fractions more concretely, namely the meaning of the fraction itself and the concept of a equal fraction.

3. Determine the fraction number and prove whether the fraction is equal or not

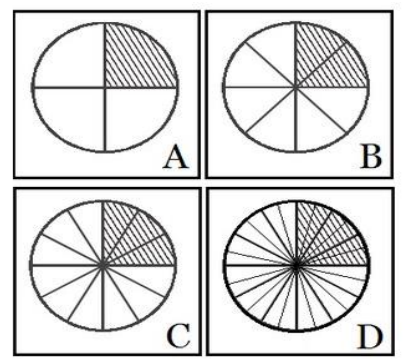

In Figure A, it can be seen that there is 1 part of the circle shaded and there are 4 parts in total, so that in Figure A if written as a fraction is $1 / 4$. Likewise in Figure $\mathrm{B}$, there are 2 shaded parts of the circle and a total of 8 parts, so it is written 4/8. Figures $C$ and D in the same way it can be written in the form of fractions, namely $3 / 12$ and $6 / 24$. Furthermore, the shaded part in pictures $\mathrm{A}, \mathrm{B}, \mathrm{C}$ and $\mathrm{D}$ is the same as a quarter of a circle, so it can be concluded that the four images have the same value, or can be written:

$1 / 4=4 / 8=3 / 12=6 / 24$

4. Adding the fractions by using manipulative media

For example, the sum of $1 / 3+1 / 2=\ldots$

The steps are as follows: a. Make a rectangle on the plywood provided.

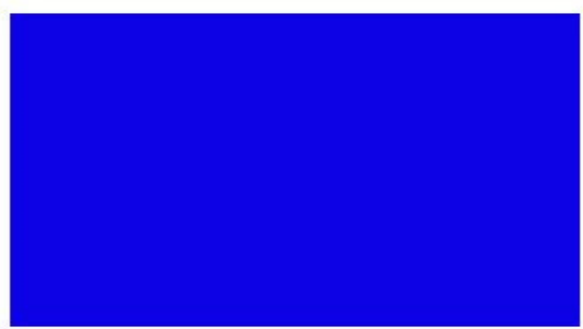

b. Divide the rectangle into three equal parts (because of the denominator of the first number 3 )

c. From the other side, divide the rectangle into two equal parts (because the denominator of the second number is 2)

d. Place the red mangosteen paper $1 / 3$ of the vertical side, and the yellow mangosteen paper $1 / 2$ of the horizontal side.

e. In the experiment there is a box that contains two colors, move one of the colors to the empty box.

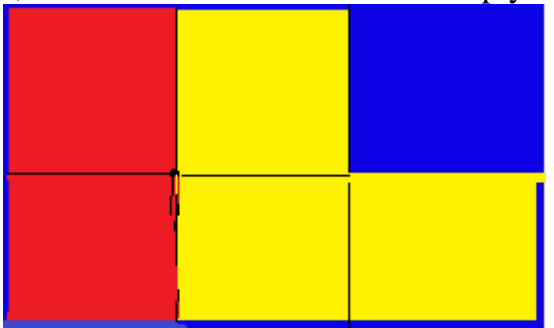

f. Count how many red and yellow squares (there are 5 squares), as well as all the available boxes (there are 6 boxes), so we can conclude that $1 / 3+1 / 2=5 / 6$.

Based on the example above, it can be seen that explaining the concept of fractions by using the manipulative media is more concrete. The student can imagine what the fractions are like, also understand more about the equal fraction Furthermore, adding the fraction can also be directly practiced by using manipulative media. This causes the student can experience learning directly, is more meaningful and more inherent in the students' memory, so that the concept of the fraction is better understood because they are not only taught the procedures to solve them, but more emphasis is placed on understanding the concept of fraction themselves. For example, what is meant by a fraction, why is that fraction the same as another fraction and how is the concept of adding fractions if the denominators are not the same.

This is in accordance with what was stated by [19] that students will be more concentrated and more enthusiastic if the mathematics learning is carried out by giving real or real forms and the student experience directly such as by using this manipulative media.. Students will also be more active because they immediately practice by using the manipulative media. Thus using manipulative media is an alternative method for solving fraction questions so that students' understanding of the concept of the fraction becomes better and more meaningful. 


\section{CONCLUSION}

An alternative method of solving problems about the fraction by using the manipulative media, namely in the form of paper that can be folded or shifted is more fun, more attractive in terms of appearance and easier to understand because it is more concrete in nature and students immediately practice by using media. The learning is easier to absorb and remember and more meaningful for the student. The student become more aware of the concept of fractions themselves. It is suggested that the teacher can apply this alternative method in class, especially for the student who does not understand about the conventional method in solving the fraction problem.

\section{REFERENCES}

[1] Yensy NA. An Easy and Fun Alternative to Squaring Integers. Proceedings of the National Seminar on Chemical Education, p: 20-24, ISBN: 978-623-7074-32-8, Chemical Education Study Program, FKIP UNIB, Bengkulu. 2019.

[2] Yensy N A, The Elementary Mathematics Training by Using KPK and FPB Boxes for Elementary School Teachers in Pondok Kelapa District, Scientific Journal of Development and Application of Science and Technology: Dharma Raflesia, 15th Edition No. 1 June 2017 p: 17-28, ISSN: 16938046, LPPM UNIB, Bengkulu.

[3] Yensy N A, Algebra Block Assisted Active Learning Training for Teachers of SMP N 1 Pondok Kelapa. Scientific Journal of Development and Application of Science and Technology: Dharma Raflesia, 16th Edition No. 1 June 2018, p: 73-80, ISSN: 1693-8046, LPPM UNIB, Bengkulu.

[4] Muhsetyo. The Elementary Mathematics Learning, Open University, Jakarta. 2017.

[5] Yensy N A, The Alternative Multiplication Method Training for Teachers of SD N 10 Pondok Kelapa, Scientific Journal of Development and Application of Science and Technology: Dharma Raflesia, 18th Edition No. 1 June 2020, p: 35-46, ISSN: 16938046, LPPM UNIB, Bengkulu.

[6] Yuniati, S. Determine the KPK and FPB by using the PEBI Method. BETA Journal. Volume 5 No. 2 (November) 2012. p: 149-165. p-ISSN: 2085-5893 / e-ISSN: 2541-0458. UIN Suska, Riau.

[7] Herlina,C. Efforts to Test the Effectiveness of Teaching by Using Teaching Aids That Will Be Compared with Teaching Without Using Teaching Aids. Semarang : UNNES. 2015.

[8] Pujiati. The Use of Teaching Aids in Elementary Mathematics Learning. Yogyakarta : Depdiknas. 2014.

[9] Marno. The Efforts to Improve Students' Understanding of the Concept of Fractions by Using The Manipulative Objects (Classroom Action Research in Class III SD Experiment
Negeri Pajagalan 58 Bandung). UPI Bandung Thesis: Not Published. 2010.

[10] Blanke, B. Using Visual Model for Strategic Reasoning in Mathematics. 2011 [online]. Available:

http://www.mathlearningcenter.org/media/rekenre k_0308.pdf [accessed March 15, 2019].

[11] Azizan, U. H. and Ibrahim, F. Misconceptions in Comparing Fractions among Primary School Pupils in Malaysia. International Journal of Social Science Tomorrow. Vol 1, No 2, ISSN 2277-6168, 2012, p 43-55.

[12] Savitri, M.E; Mardiyana \& Subanti, S. Analysis of Student Misconceptions on Fractions in Algebraic Form in terms of Cognitive Style of Class VIII Students at SMP N 2 Adimulyo, Kebumen Regency. Journal of Electronic Mathematics Learning.Vol.4, No.4, ISSN: 2339-168. 2016, p: 401-413.

[13] Yelisa, M. Increasing the Summing Ability of Simple Fractions through the Media of Cuisenaire Bars for Children with Learning Difficulties X. Special Education Scientific Journal. Vol 4 No 3 (September 2015). p :224-233.

[14] Karnia, N. The Teaching Aid for Understanding the Concept of Fractions. Journal of THEOREMS (The Original Research of Mathematics) Vol. 2 No. 2, January 2018, p: 1-12.

[15] Arifin, S. The Manipulative Media for Elementary Mathematics Learning: Fraction Operation Material. Jakarta: PT. Raja Grafindo. 2020.

[16] Yilmaz, S \& Tekin Dede, A, Mathematization Competencies of Pre - Service Elementary Mathematics Theachers In The Mathematical Modelling Process. International Journal of Education In Mathematics, Science and Technology 4(4), 2016, p 284 - 298.

[17] Agustina, A; Utomo, B.T; Lovi, C, Improving mathematical ability and student learning outcomes through realistic mathematic education (RME) approach. International Journal of Engineering \& Technology. 7 (2.10), 2018, p 5557.

[18] Olivier. Study and Investigation of the Problem and Learning Disorders of Student by Various Cognitive Style in Mathematics Course at Rasht Shahid Chamran Higher Education Center. The Journal of Mathematics and Computer Science. Vol 1, No 3, 2008, p 216-229.

[19] Perminov, Evgeniy A, On The Research of The Methodology of Mathematization of Pedagogical Science. International Journal of Environmental \& Science Education 11(16), 2016, p 9339 - 9347. 